\title{
Evidence of Structural Cavities in 3D Printed Acetabular Cups for
}

\section{Total Hip Arthroplasty}

Harry Hothi ${ }^{a}$, Lorenzo Dall'Ava ${ }^{\text {a }}$, Johann Henckel ${ }^{\text {a }}$, Anna Di Laura ${ }^{\text {a }}$, Francesco Iacoviello ${ }^{\text {b }}$, Paul Shearing ${ }^{\mathrm{b}}$, Alister Hart ${ }^{\mathrm{a}}$

a. Institute of Orthopaedics and Musculoskeletal Science, University College London and the Royal National Orthopaedic Hospital, Stanmore HA7 4LP, United Kingdom

b. Electrochemical Innovation Lab, Department of Chemical Engineering, University College London, Torrington Place, London WC1E 7JE, UK

Corresponding Author:

Harry Hothi and Lorenzo Dall'Ava

Institute of Orthopaedics and Musculoskeletal Science, University College London, Royal

National Orthopaedic Hospital, Brockley Hill, Stanmore, HA7 4LP, UK

Email: h.hothi@ucl.ac.uk;

lorenzo.dallava.17@ucl.ac.uk 


\begin{abstract}
The use of three-dimensional (3D) printing to manufacture off-the-shelf titanium acetabular cups for hip arthroplasty has increased, however the impact of this manufacturing technology is yet not fully understood. Although several studies have described the presence of structural cavities in 3D printed parts, there has been no analysis of full post-production acetabular components.

The aim of this study was to investigate the effect of 3D printing on the material structure of acetabular implants, first comparing different designs of 3D printed cups, secondly comparing 3D printed with conventionally manufactured cups.
\end{abstract}

Two of the 3D printed cups were produced using electron beam melting (EBM), one using laser melting (LRM). The investigation was performed using x-ray microcomputed tomography, imaging both the entire cups and samples sectioned from different regions of each cup.

All 3D printed cups showed evidence of structural cavities; these were uniformly distributed in the volume of the samples and exhibited a prevalent spherical shape. The LRM-manufactured cup had significantly higher cavity density $(p=0.0286)$, with a median of 21 cavities $/ \mathrm{mm}^{3}$ compared to 3.5 cavities $/ \mathrm{mm}^{3}$ for EBM cups. However, the cavity size was similar, with a median of $20 \mu \mathrm{m}$ ( $p$ $=0.7385)$. The conventional cups showed a complete absence of distinguishable cavities.

The presence of cavities is a known limitation of the 3D printing technology, however, it is noteworthy that we found them in orthopaedic implants used in patients. Although this may impact their mechanical properties, to date, 3D printed cups have not been reported to encounter such failures. . 


\section{Keywords}

3D Printing, Additive manufacturing, Structural cavities, Orthopaedic implants, Acetabular cups

Running heads: Structural cavities in 3D printed acetabular cups 


\section{Introduction}

Three-dimensional (3D) printing methods are increasingly being used to manufacture off-the-shelf titanium acetabular cups for total hip arthroplasty (THA); these are designed with highly porous backside surfaces with the aim of achieving enhanced fixation with bone when compared with conventionally manufactured (i.e. non-3D printed) cups ${ }^{(1),(2)}$. The number of 3D printed cup designs has grown 3-fold in the past decade and over $10 \%$ of all cementless revision cups used in the United Kingdom (UK) are now 3D printed ${ }^{(3)}$.

3D printing methods involve a completely different approach to manufacturing compared to traditional methods such as forging and machining. These implants are built layer-over-layer, melting titanium powder using an energy source (laser or electron beam) in a controlled environment ${ }^{(4)}$. The implications of this different manufacturing method are not fully understood and there are risks of defects in the solid structure which may have an impact on the mechanical properties ${ }^{(5)}$.

Whilst several studies have investigated the presence of defects using phantom models, ad-hoc manufactured samples ${ }^{(6),(7)}$ and general medical implants ${ }^{(8)}$, there has been no independent analysis of full post-production acetabular cups.

The aim of this study was to investigate the effect of 3D printing on the material structure of acetabular cups produced using this manufacturing technology. Our first objective was to compare different designs of 3D printed acetabular cups and our second objective was to compare 3D printed with conventionally manufactured acetabular cups. 


\section{Materials and methods}

The study design is summarised in Figure 1.

\subsection{Materials}

We acquired six titanium acetabular cups consisting of six different designs from four manufacturers. The cups were divided into two groups according to their manufacturing method: '3D printed' $(\mathrm{n}=3)$ and 'conventional' $(\mathrm{n}=3)$. Table 1 summarizes the details of the cups. The 3D printed cups had been manufactured starting from Titanium-6-Aluminium-4-Vanadium (Ti6Al4V) alloy powder using two processes: Electron Beam Melting (EBM; Delta TT and Mpact 3D Metal) and Laser Rapid Manufacturing (LRM; Trident II Tritanium).

The Delta TT cup is the most used 3D printed off-the-shelf acetabular design in UK ${ }^{(3)}$, whilst Trident II Tritanium and Mpact 3D Metal have been recently introduced on the market. The conventional cups are made of Ti6Al4V alloy and are among the most used cementless acetabular design in $\mathrm{UK}^{(3)}$.

\subsection{Methods}

We used x-ray microcomputed tomography (micro-CT) to perform high-resolution imaging of all cups; we first imaged the entire component, followed by sectioning and reimaging of the sectioned samples at a higher resolution. The extent and distribution of potential internal cavities were then measured from this imaging.

\subsubsection{X-ray microcomputed tomography of the whole cups}

A micro-CT scanner (XTH 225, Nikon Metrology, UK) equipped with a Tungsten target was used to scan the whole volume of the acetabular cups. The $\mathrm{x}$-ray beam was set to a voltage of $150 \mathrm{kV}$ and current of $70 \mu \mathrm{A}$; a $\mathrm{Cu}$ hardware filter of $0.25 \mathrm{~mm}$ was located at the beam source to reduce the beam hardening effect present with metallic samples. The scanning process included a 
complete $360^{\circ}$ rotation of the samples at a step size of $0.11^{\circ}$, with 3,177 views, 1 frame per view and exposure time of $1000 \mathrm{~ms}$, resulting in a total scan time per sample of $53 \mathrm{~min}$. The resolution (voxel size) at which the images were acquired was in the range $32-38 \mu \mathrm{m}$ (Figure 2a).

The $2 \mathrm{D}$ projection images acquired during the scans were reconstructed importing the data into CT Pro 3D software (version 4.4, Nikon Metrology, UK) using a filtered back-projection algorithm. A further reduction of the beam hardening effect was possible applying a numerical filtering (polynomial correction of second order) during the reconstruction process (Figure 2b).

The reconstructed volumes were imported in the 3D micro-CT analysis software Avizo (version 9.0, Thermofisher Scientific, US); the images were binarized using a built-in automatic segmentation process based on the 'iso-50\%' principle, choosing a specific edge grey value for each implant. An example of a rendered volume is shown in Figure 2c. The segmentation threshold corresponded to the mid-grey-level between the peaks that coincide with the irradiated materials (in our case metal alloy and air as background) in the histogram plot of voxels count versus voxel intensity (grey-scale value).

\subsubsection{Implant sectioning}

A water-cooled diamond coated band saw (Exakt, Germany) was used to obtain 4 samples from specific regions of each acetabular component (24 sample in total). Table $\mathbf{2}$ summarizes the area from where the samples were sectioned. The samples had dimensions of approximately $6 \mathrm{~mm} x$ $12 \mathrm{~mm} \times 6 \mathrm{~mm}$ (width, height, depth). The parts of the cups that were clamped during the sectioning process to hold the implant were discarded and no samples were selected from those areas to avoid any possible bias given by the setup. Figure $\mathbf{3}$ shows the six cups and the corresponding sectioned samples.

\subsubsection{X-ray microcomputed tomography of the sectioned samples}


The 24 sectioned samples were scanned using the same micro-CT scanning setup used with the whole acetabular cups. The beam voltage was kept at $150 \mathrm{kV}$, whilst the beam current was set at $50 \mu \mathrm{m}$, in order to obtain optimal X-ray penetration and image contrast. A hardware Cu filter of $0.1 \mathrm{~mm}$ was used in this case. The scanning process included again a complete $360^{\circ}$ rotation of the samples at a step size of $0.11^{\circ}$, with 3,177 views, 1 frame per view and exposure time of $1000 \mathrm{~ms}$, resulting in a total scan time per sample of 53 min.

The smaller dimensions of the sectioned samples allowed to increase the image resolution to $5 \mu \mathrm{m}$. The reconstruction process was performed in the same manner as that used with the whole acetabular cups; the binarization of the images was developed using the automatic 'iso-50\%' segmentation.

The outcome of the micro-CT analysis for both the whole cups and the sectioned samples were investigated using the software Avizo (version 9.0, Thermofisher Scientific, US). First, the different 3D printed acetabular designs were compared; then, 3D printed cups were compared to conventional. For each sample we evaluated (1) the density of the cavities (number/ $\mathrm{mm}^{3}$ ), (2) shape, (3) size (equivalent diameter), (4) volume of the cavities and (5) the material volume fraction.

\subsection{Statistical analysis}

Statistical analysis was performed using the statistical software package Prism (version 7.01, GraphPad, US). Non parametric Kruskal-Wallis and subsequent post hoc Dunn's multiple comparison tests were used to determine differences among the four samples obtained from each 3D printed cup, among samples from corresponding regions of the different 3D printed cups and among the overall 3D printed cups. The level of significance for all statistical analyses was $\mathrm{p}<$ 0.05 . 


\section{Results}

The results of the comparative analysis of different 3D printed acetabular cups are presented first, followed by the results of the comparative analysis of 3D printed and conventional cups.

\subsection{Comparison of 3D Printed Cup Designs}

\subsubsection{Whole Cup Analysis}

The micro-CT outcomes of the whole volume of the 3D printed cups suggested that some cavities were present in the material structure; these were identified in the Delta TT and Mpact 3D Metal cups, but not in the Trident II Tritanium. Example of the grey scale and binarized cross-section slices of the 3D printed cups where the cavities were found are shown in Figure 4. The defects were located in different regions of the two cups. Since the image resolution of the scans of the whole cups was 32 - $38 \mu \mathrm{m}$, all the cavities sized below $50 \mu \mathrm{m}$ were discarded. Thus, the number of distinguishable cavities in the Delta TT cup were 11, whilst 3 were found in the Mpact 3D Metal cup. The median (interquartile range, IQR) size of these cavities were $64.7 \mu \mathrm{m}$ (50.8 to 152) and $84.4 \mu \mathrm{m}$ (58 to 86.4$)$, respectively.

\subsubsection{Sectioned Cup Analysis}

Micro-CT analysis at higher resolutions performed on the sectioned samples confirmed the presence of cavities in the Delta TT and Mpact 3D Metal cups and revealed cavities in the Trident II Tritanium cup. This was true for all samples from the different areas of the cups.

The image resolution of the scans was approximately $5 \mu \mathrm{m}$, thus all the cavities with a size below $10 \mu \mathrm{m}$ were discarded. The measurements of cavity density, size, volume and material volume fraction for the four sectioned samples from each 3D printed cup are reported in Table $\mathbf{3}$.

The presence and the distribution of the cavities in the samples obtained from the Delta TT, Mpact 3D Metal and Trident II Tritanium cups are shown in Figure 5. Region of interest located entirely 
within the dense part of the samples were extrapolated and the voxels labelled as material during the segmentation process were inverted to become background (and vice versa). This provided a visual representation of the cavities as material. The shape of the cavities was spherical on average, as shown by both the cross-section and the cavity distribution images. A 3D-shape factor of the cavities was also measured, obtaining mean values of $1.465,1.195$ and 1.503 for the Delta TT, Mpact 3D Metal and Trident II Tritanium cups, respectively; a perfect sphere is depicted by a value of 1 .

\subsubsection{Intra-cup analysis}

Significant differences in the cavity size and volume were found among the different areas on the Delta TT cup: the sample obtained from the porous region had smaller cavities than the central hole $(p=0.0137)$, the screw hole $(p=0.0383)$ and the edge areas $(p=0.0392)$. There were no differences among the samples sectioned from the other regions.

There were no significant differences in the size and volume of the cavities among the four samples from the Mpact 3D Metal cup. Similarly, the Trident II Tritanium cup showed no significant differences among the four regions in terms of size and volume of the cavities.

\subsubsection{Inter-cup analysis: corresponding samples}

Comparing the outcomes from corresponding regions of the different $3 \mathrm{D}$ printed cups, significant differences were found in the size and volume of the cavities between Delta TT and Mpact 3D Metal $(p<0.0001)$ and Trident II Tritanium and Mpact 3D Metal $(p<0.0001)$ in the screw hole area, whilst no difference was present between Delta TT and Trident II Tritanium. The Mpact 3D Metal cup showed smaller cavities than the others in this region. A significant difference was also found between Delta TT and Trident II Tritanium in the porous area $(p=0.0481)$, whilst there was no difference between Delta TT and Mpact 3D Metal $(p=0.0604)$ and between Trident II 
Tritanium and Mpact 3D Metal $(p>0.9999)$. Similar cavity size and volume were shown in the central hole and edge areas. Figure $\mathbf{6}$ plots the cavity size for the 3D printed cups grouped by areas on the cups from where the samples were obtained.

\subsubsection{Inter-cup analysis: overall cups}

We found significantly higher cavity density in the Trident II Tritanium cup compared to Delta TT and Mpact 3D Metal $(p=0.0286)$ (Figure 7). The median (IQR) values were 3.511 cavities $/ \mathrm{mm}^{3}$ (2.314 to 6.778$), 3.645$ cavities $/ \mathrm{mm}^{3}$ (2.841 to 4.048$)$ and 21.87 cavities $/ \mathrm{mm}^{3}$ (20.64 to 54.57) for Delta TT, Mpact 3D Metal and Trident II Tritanium, respectively. No significant difference was found in cavity density between Delta TT and Mpact 3D Metal $(p=0.8857)$.

This difference among the cups is reflected also in the material volume fraction. The Trident II Tritanium showed a significant lower value compared to the others $(p<0.0001)$, whilst no difference was present between Delta TT and Mpact 3D Metal $(p>0.9999)$. The median (IQR) values were $99.9906 \%$ (99.9833 to 99.9988$)$ ), $99.9902 \%$ (99.9817 to 99.9986$)$ and $99.9709 \%$ (99.8721 to 99.9874) for Delta TT, Mpact 3D Metal and Trident II Tritanium, respectively.

No significant difference in the cavity size was found between Delta TT and Trident II Tritanium $(p=0.7427)$, Delta TT and Mpact 3D Metal $(p>0.9999)$ and Trident II Tritanium and Mpact 3D Metal $(p=0.7421)$. Similarly, there was no significant difference in the cavities volume between Delta TT and Trident II Tritanium ( $p=0.7386)$, Delta TT and Mpact 3D Metal $(p>0.9999)$ and Trident II Tritanium and Mpact 3D Metal $(p=0.7482)$. The median (IQR) sizes were $20.62 \mu \mathrm{m}$ (10.15 to 135.1$), 19.09 \mu \mathrm{m}$ (10.16 to 137.6$)$ and $20.51 \mu \mathrm{m}$ (10.29 to 78.25$)$; the median (IQR) volumes were $4,588 \mu \mathrm{m}^{3}$ (548.2 to $\left.1,292,040\right), 3,645 \mu \mathrm{m}^{3}$ (549 to $\left.1,363,180\right)$ and $4,517 \mu \mathrm{m}^{3}(569.9$ to 250,829 ) for Delta TT, Mpact 3D Metal and Trident II Tritanium, respectively. The distribution of the cavity size for the 3D printed cups is plotted in Figure $\mathbf{8}$. 


\subsection{Comparison of $3 D$ printed and Conventional Cups}

The micro-CT outcomes of the whole conventional cups showed an absence of distinguishable structural cavities. Micro-CT analysis of sectioned samples of the conventional cups confirmed the absence of cavities in all the cups. Figure 9 shows a comparison between 3D printed and conventional cups. 


\section{Discussion}

This is the first comparative study to investigate the effect of $3 \mathrm{D}$ printing on the material structure of different designs of acetabular cups used in hip replacement surgery. Our main finding was the presence of structural cavities in all 3D printed cups, with a significantly higher cavity density (> 20 cavities $/ \mathrm{mm}^{3}$ ) present in the laser-manufactured cup (Trident II). Interestingly we found a complete absence of structural cavities in the conventionally manufactured cups. Whilst these cavities are a known theoretical by-product of the 3D printing process ${ }^{(4),(9)}$, their prevalence in implants that are to be used in patients is noteworthy. However, no mechanical failures of 3D printed acetabular cups have been reported in literature, suggesting that these cavities do not affect their mechanical or clinical performance.

Several studies have investigated the presence and shape of cavities in 3D printed parts ${ }^{(5)-(8),(10)-(12)}$, but this is the first study to identify and characterize the cavities in 3D printed medical components that are implanted for joint arthroplasty. These 3D printed cups are used both in Europe and in the United States, having received CE marking and approval under the Food and Drug Administration 510(k) (13)-(15). All the cups were cleared under the substantial equivalence provision, after mechanical tests had been conducted to evaluate their performance. Good clinical outcomes in the short and mid-term have been reported for the Delta TT cup, which was introduced in $2007^{(16)-(19)}$. This cup has been used in 5\% (out of 4,006) of the revision cases performed in the United Kingdom in 2017; a similar 3D printed design produced by the same manufacturer has been implanted in the same year in $6 \%$ of the revision procedures ${ }^{(3)}$. The Mpact 3D Metal and Trident II Tritanium cups have been recently introduced on the market.

The numbers of 3D printed implants are expected to grow rapidly, considering both the increasing adoption of 3D printing manufacture for the production of off-the-shelf acetabular components and the projected increase in the number of patients requiring hip replacement surgery ${ }^{(20),(21)}$. 
The cavities discovered in this study were predominantly spherical in shape; it has previously been suggested that these may occur as a result of gaps within the starting powder beads, entrapment of gas molecules from the build chamber atmosphere during the building process (keyhole melting) or because of sub-optimal building parameters ${ }^{(22),(23)}$.

The sizes of the cavities were comparable between the different designs, with a median diameter of $20 \mu \mathrm{m}$, ranging from 10 to $130 \mu \mathrm{m}$. The presence of small cavities $(<20 \mu \mathrm{m})$ may be due to gas entrapment during the melting and solidification of the layered structure or to incomplete remelting of previous layers during the building process. However, some of these cavities may be due to voids within the titanium powder, which is commonly produced via gas atomization process. With this technique the Ti6Al4V alloy is converted from a molten state to spherical shaped particles (atomization) using a flow of argon and nitrogen gas at high pressure ${ }^{(22)}$; the fast solidification in the particle shape is subjected to entrapment of gas, which results in the presence of cavities. These cavities can be transferred to the final part without being removed during the 3D printing process because the powder size and the layer thickness (i.e. the dimension of each layer that makes the final part) are similar. The nominal powder size and the layer thickness in EBM and LRM are $45-106 \mu \mathrm{m}$ and $10-45 \mu \mathrm{m}, 10-50 \mu \mathrm{m}$ and around $50 \mu \mathrm{m}$, respectively. Therefore, it can be speculated that if the structural cavities in the 3D printed cups were due to cavities already present in the powder particles, then the size of the cavities would similar between the two processes because the powder particles, albeit being smaller in diameter in LRM, were produced using similar processes. These cavities would then be transferred to the final component, independently of the metal 3D printing technique.

Iebba et al. ${ }^{(23)}$ reported evidence of spherical cavities present in EBM- and SLM-manufactured parts below $10 \mu \mathrm{m}$ in diameter. The detection of cavities of this size was beyond the resolution of the current scanner ${ }^{(24)}$ and we cannot exclude that cavities smaller than $10 \mu \mathrm{m}$ may have been present in the samples analysed. 
The presence of larger spherical cavities can be attributed to the coalescence of multiple cavities present in the starting powder. The entrapment of gas pores into the molten pool (i.e. the area melted by the energy beam before the re-coating with unmolten powder occurs) may also occur as the build chamber of both EBM and LRM processes are filled with inert gasses, Helium and Argon/Nitrogen, respectively. Inert gasses are insoluble in liquid metals, thus, unless the entrapped pores escape from the molten pool, cavities are likely to form in the solidified part ${ }^{(22)}$.

It has also been reported that sub-optimal building conditions can lead to different type of cavities (4),(7),(8),(22) and that this can influence the mechanical properties of the final part ${ }^{(6),(10),(12)}$, especially the fatigue strength ${ }^{(11)}$. Gong et al ${ }^{(10)}$ suggested that any significant variation of the EBM process parameters can lead to the formation of large defects and poor mechanical properties. If the energy input is higher than the optimum, the mechanical properties of SLM-produced parts can be affected if the material volume fraction is reduced of 5\%; whilst, even $1 \%$ of cavities can detrimentally influence the mechanical properties if an insufficient energy input is used.

We found a significant difference in the material volume fraction of EBM-manufactured and LRM-manufactured cup, with the latter showing values as low as $99.9487 \%$ in one of the sectioned samples. Generally, parts built with $0.5 \%$ porosity or less are considered sufficiently dense ${ }^{(7)}$; in our study, the highest value was slightly above $0.05 \%$, thus suggesting that the $3 \mathrm{D}$ printed cups were generally well manufactured and the process parameters for both EBM-manufactured and LRM-manufactured cups were optimal.

It is interesting that we found a significantly higher cavity density ( $>20$ cavities $\left./ \mathrm{mm}^{3}\right)$ in the LRMmanufactured cup but similar cavity sizes. This difference between EBM and LRM could be attributed to the several factors. First, the smaller powder particle size in LRM entails that more particles need to be melt together to obtain a specific length, compared to EBM where the particles are bigger, thus implying that more cavities, if present in the powder particles, could be entrapped 
in the final component per $\mathrm{mm}^{3}$. Secondly, a combination of lower temperature inside the LRM build chamber $\left(100-200{ }^{\circ} \mathrm{C} ; 400-1000{ }^{\circ} \mathrm{C}\right.$ in EBM), lower heat source energy (laser beam up to $1 \mathrm{~kW}$, electron beam around $60 \mathrm{~kW}$ ), lower scan speed in LRM (i.e., speed at which the energy source melts the powder particles) and higher cooling rate experienced with LRM may have contributed to create more structural cavities, compared to EBM. It may be that the cavities produced during EBM have been eliminated more efficiently thanks to the more powerful source, the faster scanning and the slower cooling rate. Furthermore, these parameters affect the interplay between the different physics processes happening during the melting of the metal powder. It has been suggested that upon cooling the surface tension of the material (Marangoni effect) has a dominant role and is involved in the formation of the structural cavities; the high cooling rate in LRM would then lead to the creation of a greater number of cavities, compared to EBM ${ }^{(25)}$.

The 3D printed parts produced using laser melting are also usually subjected to heat post-treatment processes in order to reduce the residual stresses and the potential defects in the structure. These heat treatments usually involve temperature in the range $700-900{ }^{\circ} \mathrm{C}$, which is below the melting temperature of the Ti6Al4V alloy. The LRM-manufactured cup analysed in this study has been heat treated, although the specific temperature and duration are proprietary.

Leuders et al ${ }^{(11)}$ found that with post-processing most residual cavities were removed, although the analysis was performed using micro-CT with a $22 \mu \mathrm{m}$ resolution, meaning that any cavity size below $44 \mu \mathrm{m}$ (i.e. $2 \mathrm{x}$ scanning resolution) was likely undetectable.

It is unclear if the higher cavity density shown in the LRM- manufactured cup, compared to the EBM-manufactured ones, would result in lower mechanical properties. Theoretically, cavities of the same size but in higher prevalence $\left(\right.$ number $/ \mathrm{mm}^{3}$ ) would provide less mechanical strength, however there is no clinical evidence to suggest that this is the case. The LRM-manufactured cup 
has been recently introduced on the market and clinical outcomes are yet to be published. Furthermore, this cup has been cleared to be used in patients both in Europe and in the United States, thus implying that all the mechanical requirements have been met; however, examples of implants cleared for commercialization that have been subsequently removed from the market are present in orthopaedics.

The 3D printed cups are used in non-cemented cases and the insertion of the cup into the acetabular cavity is performed press-fitting the implants into a 1-2 mm under-reamed cavity using a cup impactor and a surgical mallet. The forces experienced by the cup range between 0.5 and $8 \mathrm{kN}$, however force above $5 \mathrm{kN}$ are likely to cause breakage of the underlying bone ${ }^{(26)}$. The structural cavities may act as stress accumulation sites, potentially causing cracks to arise. Furthermore, once implanted, the cup is expected to last for many years while the patient performs daily activities such as walking. The fatigue life of $3 \mathrm{D}$ printed parts has been reported to be highly affected by the presence of structural cavities ${ }^{(11)}$, and together with the presence of potential cracks due to the impaction stresses, the overall mechanical integrity of the acetabular components needs to be monitored. However, to date no cases of fracture of the acetabular cup have been reported in literature, suggesting that the presence of the voids may not have a significant influence on the long-term mechanical properties of these components. We found that in the LRM-manufactured cup the cavity density was higher in the sample sectioned from the screw hole region $(\sim 54$ cavities $/ \mathrm{mm}^{3}$ ). It is unclear if this may affect the cup integrity, considering that forces are also exchanged in this area between the cup and screws.

The conventional cups were manufactured in multiple steps: the cup wall was produced using forging and machining; the porous structure on the backside surface was applied using different techniques according to the cup design. The Porocoat coating on the Pinnacle cup was made of spherical titanium beads sintered onto the substrate (i.e. the bulk of the cup) at high temperature. Similarly, the Gription coating was obtained sintering on a Porocoat substrate further layers of 
irregularly shaped titanium particles ${ }^{(27)}$. The Tritanium structure on the Trident I cup was obtained depositing commercially pure titanium $(\mathrm{CPTi})$ powder on a sacrificial porous polyurethane scaffold via physical vapor deposition (PVD); the structure was subsequently sintered at high temperature on the cup, removing the polyurethane. Several steps of powder re-coating and sintering provided the final product ${ }^{(27),(28)}$. All the implants, both 3D printed and conventional, are subjected to a final machining stage to obtain the appropriate cup-liner interface to accommodate the liner component.

All the conventional cups investigated in this study have been extensively used in hip arthroplasty practices. In $28 \%$ (out of 66,317) of the primary cases performed in the United Kingdom in 2017 a Pinnacle Porocoat cup was used. Considering the revision procedures in the same year, the Pinnacle Gription and the Trident I Tritanium cups were used in $15 \%$ and $13 \%$ (out of 4,006) of the cases, respectively ${ }^{(3)}$.

The complete absence of cavities in these cups is of note. This may be due to the different starting raw material: a dense block (usually bar-shaped) is produced completely melting the metal and the final part is subsequently obtained via drop forging or removing material via computer numerical controlled (CNC) machining ${ }^{(29)}$. Unlike 3D printing, where the metal powder is selectively melted according to the input CAD data, in conventional manufacturing the metal is completely melted before being shaped in the final product.

One of the strengths of this study is the comparison of different designs of both EBMmanufactured and laser-manufactured 3D printed cups produced by multiple manufacturers. The use of micro-CT is another strength; this investigation technique has become an established method of analysis for detecting structural defects, if a sufficiently high resolution (small voxel size) is reached ${ }^{(9)}$. Other methods can be used to inspect 3D printed parts, such as optical and electron microscopes, which are completely destructive and limited to specific cross-sections of the part under analysis. Micro-CT allows us to obtain non-destructively a 3-dimensional 
representation of the internal cavities, with more quantitative data. However, as in our study, sectioning of samples is still necessary in order to perform scans at high resolutions and detect smaller structural cavities below $30 \mu \mathrm{m}$.

A limitation of this study was the small number of acetabular components; future work should include a greater number of implants and potentially more designs, in order to extend our findings. Mechanical testing of the sectioned samples may also help to identify possible differences in the strength of the material, providing evidence of the impact of the structural cavities on the mechanical properties. 


\section{Conclusion}

This was the first study to report the presence of structural cavities in 3D printed acetabular cups used in hip arthroplasty. The comparison of different 3D printed acetabular designs from multiple manufacturers revealed that these cavities were present in both the EBM- and LRM-manufactured cups, with differences in the cavity density, but not in cavity size. The conventionally manufactured cup did not show any cavities in their structure.

The presence of structural cavities is a known potential by-product of metal 3D printing, but it is unclear if this may affect the mechanical properties or clinical performance of the cups. To date, this has not been reported; on the contrary, all the cups analysed in this study have been cleared by certified bodies both in Europe and United States and one of the EBM-manufactured cups has been used in hip arthroplasty for over a decade, showing good clinical outcomes.

Further studies including more implants and more 3D printed designs would extend these findings and help to monitor the performance of these type of orthopaedic implants. 


\section{Acknowledgment}

This research study was funded by The Maurice Hatter Foundation, the RNOH Charity, the Rosetrees Trust and the Stoneygate Trust and supported by researchers at the National Institute for Health Research University College London Hospitals Biomedical Research Centre. 


\section{References}

1. Mumith A, Thomas M, Shah Z, Coathup M, Blunn G. Additive manufacturing. Bone Joint J. 2018;100-B:455-60.

2. Murr LE. Additive manufacturing of biomedical devices: an overview. Mater Technol. Taylor \& Francis; 2018;33:57-70.

3. National Joint Registry for England, Wales NI and I of M. 15th Annual Report [Internet]. 2018 [cited 2019 Apr 1]. Available from: http://www.njrcentre.org.uk

4. Sames WJ, List FA, Pannala S, Dehoff RR, Babu SS. The metallurgy and processing science of metal additive manufacturing. Int Mater Rev. 2016;61:315-60.

5. Wits WW, Carmignato S, Zanini F, Vaneker THJ. CIRP Annals - Manufacturing Technology Porosity testing methods for the quality assessment of selective laser melted parts. CIRP Ann - Manuf Technol [Internet]. CIRP; 2016;65:201-4. Available from: http://dx.doi.org/10.1016/j.cirp.2016.04.054

6. Gong H, Rafi K, Gu H, Starr T, Stucker B. Analysis of defect generation in Ti-6Al-4V parts made using powder bed fusion additive manufacturing processes. Addit Manuf [Internet]. Elsevier B.V.; 2014;1:87-98. Available from: http://dx.doi.org/10.1016/j.addma.2014.08.002

7. du Plessis A, le Roux SG, Booysen G, Els J. Directionality of Cavities and Porosity Formation in Powder-Bed Laser Additive Manufacturing of Metal Components Investigated Using X-Ray Tomography. 3D Print Addit Manuf. 2016;3:48-55.

8. du Plessis A, le Roux SG, Booysen G, Els J. Quality Control of a Laser Additive Manufactured Medical Implant by X-Ray Tomography. 3D Print Addit Manuf. 2016;3:175-82.

9. du Plessis A, Yadroitsev I, Yadroitsava I, Le Roux SG. X-Ray Microcomputed Tomography in Additive Manufacturing: A Review of the Current Technology and Applications. 3D Print Addit Manuf. 2018;5:227-47.

10. Gong H, Rafi K, Gu H, Janaki Ram GD, Starr T, Stucker B. Influence of defects on mechanical properties of Ti-6Al-4V components produced by selective laser melting and electron beam melting. Mater Des. 2015;86:545-54.

11. Leuders S, Thöne M, Riemer A, Niendorf T, Tröster T, Richard HA, Maier HJ. On the mechanical behaviour of titanium alloy TiAl6V4 manufactured by selective laser melting: Fatigue resistance and crack growth performance. Int J Fatigue [Internet]. Elsevier Ltd; 2013;48:300-7. Available from: http://dx.doi.org/10.1016/j.ijfatigue.2012.11.011

12. Kasperovich G, Haubrich J, Gussone J, Requena G. Correlation between porosity and processing parameters in TiAl6V4 produced by selective laser melting. Mater Des [Internet]. Elsevier Ltd; 2016;105:160-70. Available from: http://dx.doi.org/10.1016/j.matdes.2016.05.070

13. Delta TT Acetabular System (K112898). 2012.

14. Trident ${ }^{\circledR}$ II Tritanium ${ }^{\circledR}$ Acetabular Shell (K161569). 2016.

15. Mpact ${ }^{\circledR}$ 3D Metal ${ }^{\mathrm{TM}}$ Implants and Augments 3D Metal $^{\mathrm{TM}}$ (K171966). 2018.

16. Steno B, Kokavec M, Necas L. Acetabular revision arthroplasty using trabecular titanium implants. Int Orthop. 2015;39:389-95. 
17. Perticarini L, Zanon G, Rossi SMP, Benazzo FM. Clinical and radiographic outcomes of a trabecular titanium ${ }^{\mathrm{TM}}$ acetabular component in hip arthroplasty: Results at minimum 5 years follow-up. BMC Musculoskelet Disord. BMC Musculoskeletal Disorders; 2015;16:1-6.

18. De Meo F, Cacciola G, Bellotti V, Bruschetta A, Cavaliere P. Trabecular Titanium acetabular cups in hip revision surgery: mid-term clinical and radiological outcomes. HIP Int. 2018;28:61-5.

19. Regis M, Marin E, Fedrizzi L, Pressacco M. Additive manufacturing of Trabecular Titanium orthopedic implants. MRS Bull. 2015;40:137-44.

20. Bozic KJ, Kurtz SM, Lau E, Ong K, Vail TP, Berry DJ. The Epidemiology of Revision Total Hip Arthroplasty in the United States. J Bone Jt Surgery-American Vol. 2009;91:128-33.

21. Patel A, Pavlou G, Mújica-Mota RE, Toms AD. The epidemiology of revision total knee and hip arthroplasty in England and Wales: A comparative analysis with projections for the United States. a study using the national joint registry dataset. Bone Jt J. 2015;97B:1076-81.

22. DebRoy T, Wei HL, Zuback JS, Mukherjee T, Elmer JW, Milewski JO, Beese AM, Wilson-Heid A, De A, Zhang W. Additive manufacturing of metallic components Process, structure and properties. Prog Mater Sci. 2018;92:112-224.

23. Iebba M, Astarita A, Mistretta D, Colonna I, Liberini M, Scherillo F, Pirozzi C, Borrelli R, Franchitti S, Squillace A. Influence of Powder Characteristics on Formation of Porosity in Additive Manufacturing of Ti-6Al-4V Components. J Mater Eng Perform. Springer US; 2017;26:4138-47.

24. Kruth JP, Bartscher M, Carmignato S, Schmitt R, De Chiffre L, Weckenmann A. Computed tomography for dimensional metrology. CIRP Ann - Manuf Technol. CIRP; 2011;60:821-42.

25. Khairallah SA, Anderson AT, Rubenchik A, King WE. Laser powder-bed fusion additive manufacturing: Physics of complex melt flow and formation mechanism of pores, spatter and denudation zones. Acta Mater. 2016;108:36-45.

26. Spears IR, Morlock MM, Pfleiderer M, Schneider E, Hille E. The influence of friction and interference on the seating of a hemispherical press-fit cup: A finite element investigation. J Biomech. 1999;32:1183-9.

27. Frank RM, Fabi D, Levine BR. Modern Porous Coatings in Orthopaedic Applications. Thin Film Coatings Biol. 2013.

28. Muth J, Poggie M, Kulesha G, Michael Meneghini R. Novel highly porous metal technology in artificial hip and knee replacement: Processing methodologies and clinical applications. Jom. 2013;65:318-25.

29. Mctighe T, Brazil D, Bruce W. Metallic Alloys in Total Hip Arthroplasty. 2015;1-12. 


\section{Tables}

Table 1 -Summary of the details of the acetabular components

\begin{tabular}{lllc}
\hline Manufacturer & Brand & Manufacturing method & Size \\
\hline $\begin{array}{l}\text { Lima Corporate } \\
\text { (San Daniele del Friuli, IT) }\end{array}$ & Delta TT & 3D printing (EBM) & $58 \mathrm{~mm}$ \\
$\begin{array}{l}\text { Stryker } \\
\text { (Mahwah, USA) }\end{array}$ & Trident II Tritanium & 3D printing (LRM) & $54 \mathrm{~mm}$ \\
$\begin{array}{l}\text { Medacta } \\
\text { (Castel San Pietro, CH) }\end{array}$ & Mpact 3D Metal & 3D printing (EBM) & $58 \mathrm{~mm}$ \\
\hline $\begin{array}{l}\text { DePuy Synthes } \\
\text { (Warsaw, USA) }\end{array}$ & Pinnacle Porocoat & Conventional (forging, machining) & $46 \mathrm{~mm}$ \\
$\begin{array}{l}\text { DePuy Synthes } \\
\text { (Warsaw, USA) }\end{array}$ & Pinnacle Gription & Conventional (forging, machining) & $54 \mathrm{~mm}$ \\
$\begin{array}{l}\text { Stryker } \\
\text { (Mahwah, USA) }\end{array}$ & Trident I Tritanium & Conventional (forging, machining) & $60 \mathrm{~mm}$ \\
\hline
\end{tabular}

EBM: electron beam melting; $L R M$ : laser rapid manufacturing 
Table 2 - Summary of the areas of the cups that were sectioned and corresponding sample number

\begin{tabular}{ll}
\hline Sample no. & Area on the acetabular cup \\
\hline 1 & Central hole located at the pole \\
2 & Hole for screw positioning \\
3 & Porous backside surface of the dome \\
4 & Edge \\
\hline
\end{tabular}


Table 3 - Summary of the median (IQR) values of size and volume of the cavities and values of cavity density and material volume fraction for the samples sectioned from the $3 D$ printed cups

\begin{tabular}{lccccc}
\hline Cup & Cup area & $\begin{array}{c}\text { Density } \\
\left(\mathbf{n o} / \mathbf{m m}^{3}\right)\end{array}$ & Size $(\boldsymbol{\mu m})$ & Volume $\left(\boldsymbol{\mu \mathbf { m } ^ { 3 } )}\right.$ & $\begin{array}{c}\text { Volume } \\
\text { fraction (\%) }\end{array}$ \\
\hline Delta TT & 2 & 4.138 & $21.95(10.55$ to 86.0$)$ & $5,541(615.7$ to 333,080$)$ & 99.9935 \\
$(E B M)$ & 3 & 2.313 & $17.92(10.15$ to 82.38$)$ & $3,015(548.2$ to 292,729$)$ & 99.9881 \\
& 4 & 2.883 & $20.74(10.16$ to 135.1$)$ & $4,672(549.7$ to $1,292,040)$ & 99.9967 \\
\hline Mpact 3D & 1 & 2.841 & $22.78(11.17$ to 137.6$)$ & $6,196(729$ to 1,363180$)$ & 99.9888 \\
Metal & 2 & 3.462 & $13.42(10.29$ to 77.63$)$ & $1,265(569.9$ to 244,920$)$ & 99.9973 \\
$(E B M)$ & 3 & 3.828 & $19.82(10.16$ to 64.89$)$ & $4,085(549$ to 143041$)$ & 99.9897 \\
& 4 & 4.048 & $18.96(10.16$ to 73.13$)$ & $3,570(549$ to 204814$)$ & 99.9910 \\
\hline \multirow{2}{*}{ Trident II } & 1 & 20.639 & $20.70(10.62$ to 67.96$)$ & $4,643(627.4$ to 164,380$)$ & 99.9487 \\
Tritanium & 2 & 54.567 & $20.41(10.62$ to 78.25$)$ & $4,454(627$ to 250,829$)$ & 99.9973 \\
$(L R M)$ & 3 & 20.676 & $19.36(10.29$ to 65.9$)$ & $3,799(569.9$ to 149,883$)$ & 99.9897 \\
& 4 & 23.072 & $20.67(10.61$ to 65.69$)$ & $4,626(625.1$ to 148,401$)$ & 99.9910 \\
\hline
\end{tabular}

$E B M$ : electron beam melting; $L R M$ : laser rapid manufacturing 


\section{Figures}

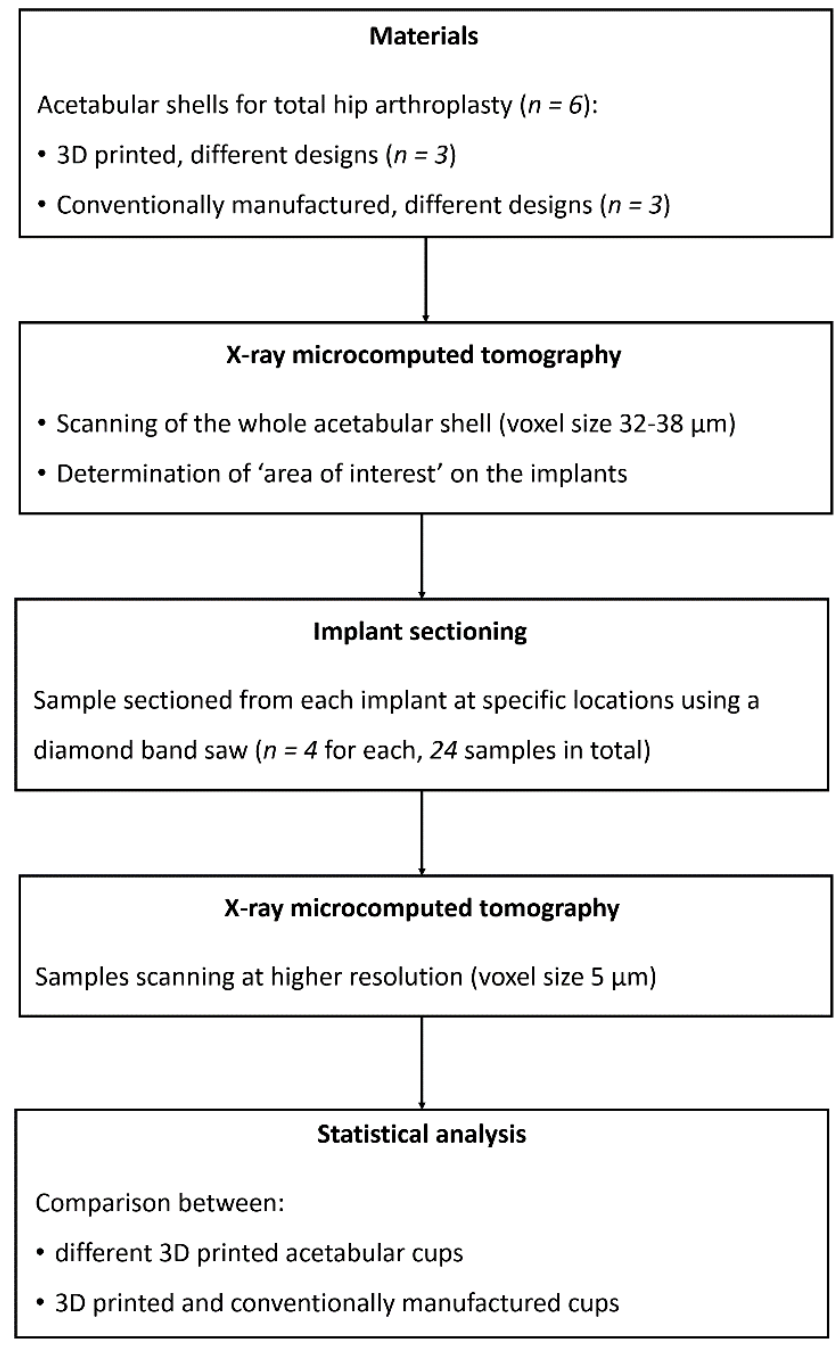

Figure 1 - Flow diagram of the design of the study 


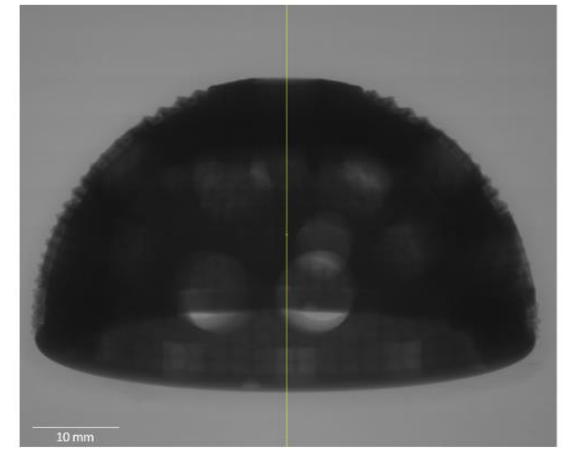

(a)

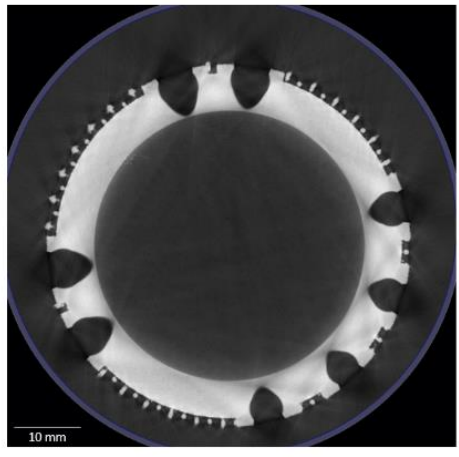

(b)

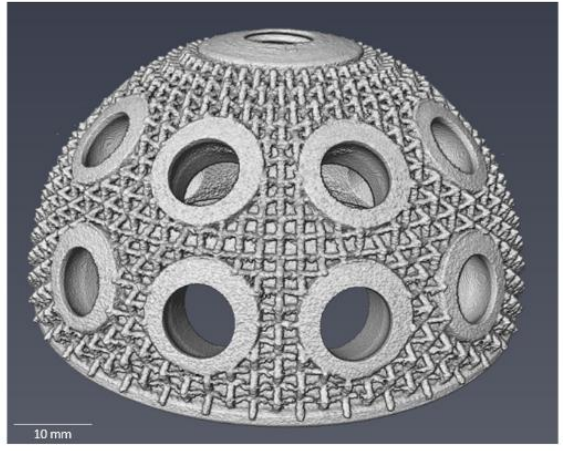

(c)

Figure 2 - Images showing the different steps of the micro-CT imaging method: (a) acetabular cup irradiated by the $x$-rays in the micro-CT scanner; (b) example of a sliced image during the reconstruction process; (c) rendered volume of the cup after the segmentation (images of the Mpact 3D Metal cup). 

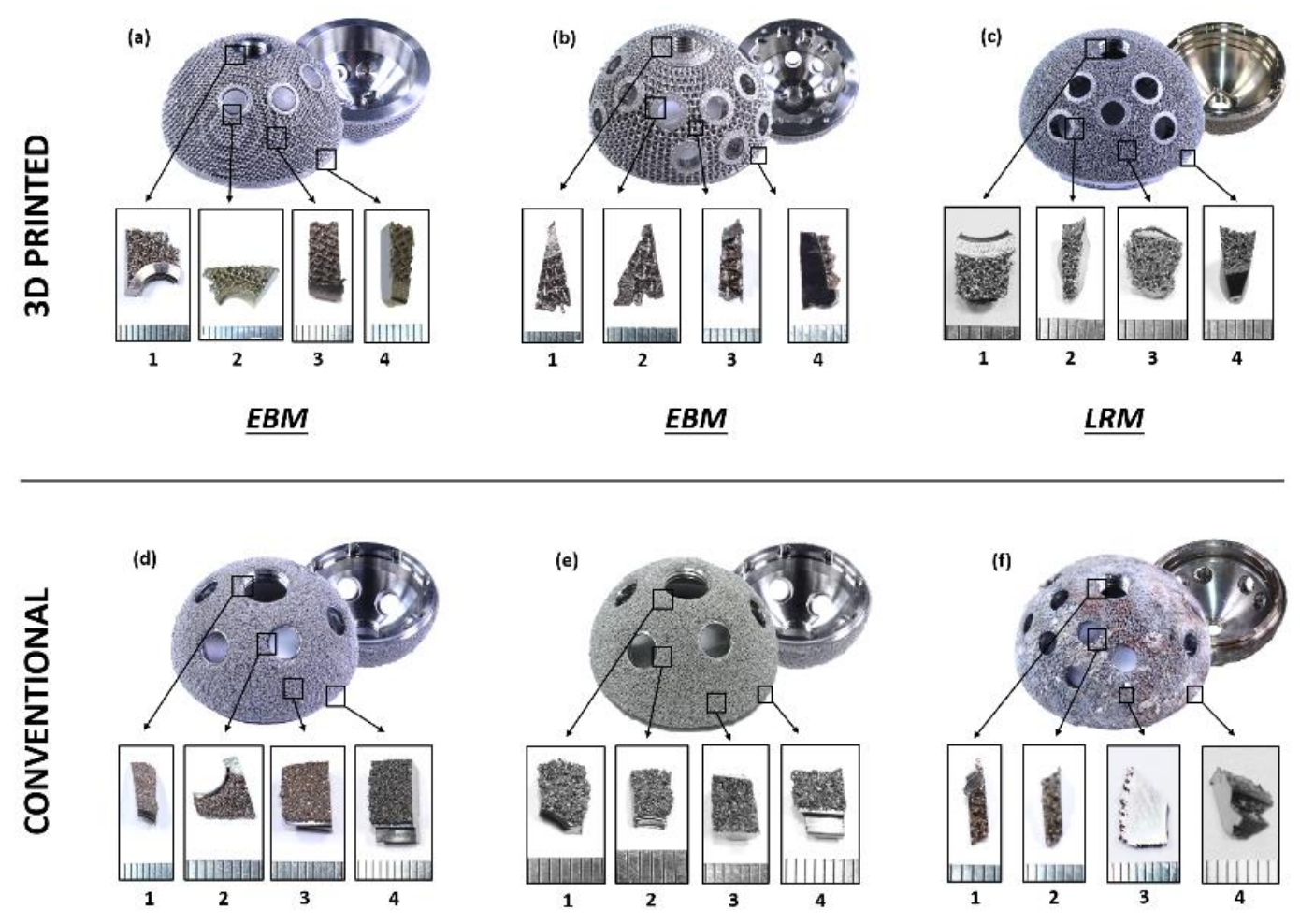

Figure 3 - Image showing the six acetabular cups (backside and internal surface) and the samples sectioned from different areas of the cups (with corresponding number): $3 D$ printed - (a) Delta TT (Lima Corporate), (b) Mpact 3D Metal (Medacta), (c) Trident II Tritanium (Stryker); conventional - (d) Pinnacle Porocoat (DePuy Synthes), (e) Pinnacle Gription (DePuy Synthes), (f) Trident I Tritanium (Stryker). 
(a)
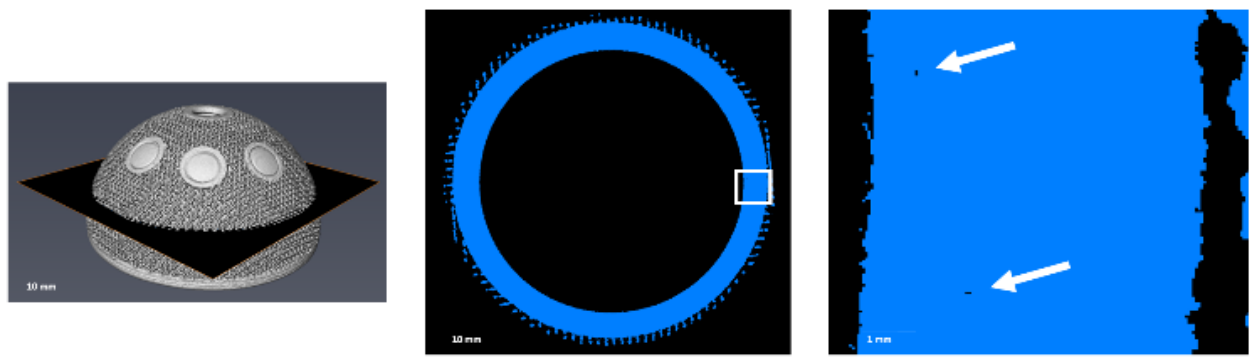

(b)
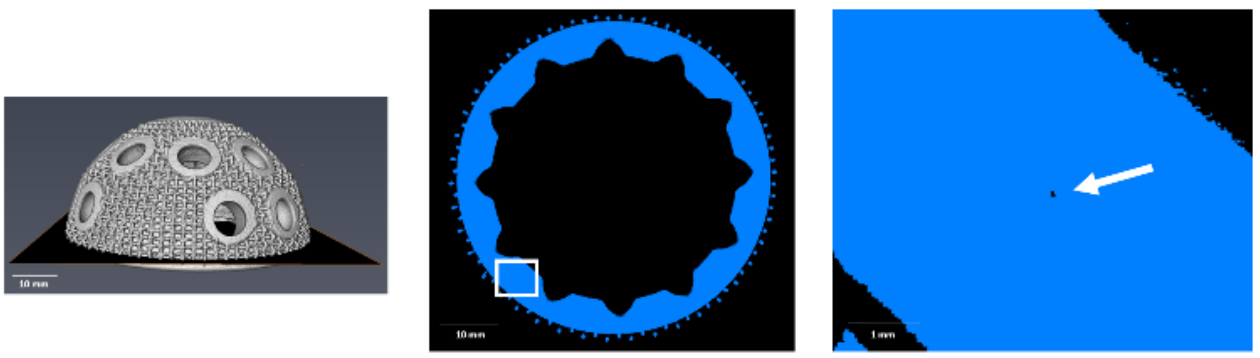

Figure 4-Images showing examples of the presence of structural cavities in two of the 3D printed cups: (a) Delta TT and (b) Mpact 3D Metal. From left to right, the location of the cross-section, the binarized slice, with the area where the cavities were found enclosed by the white rectangle, and the cavities depicted by the white arrows in the zoomed images. 
(a)

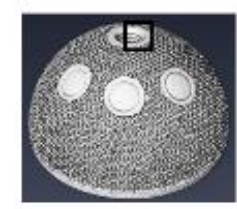

(b)
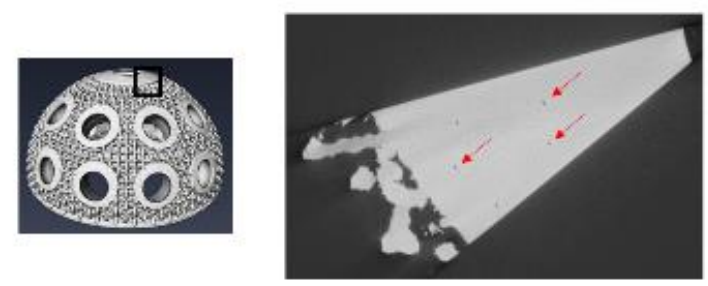

$\underline{E B M}$
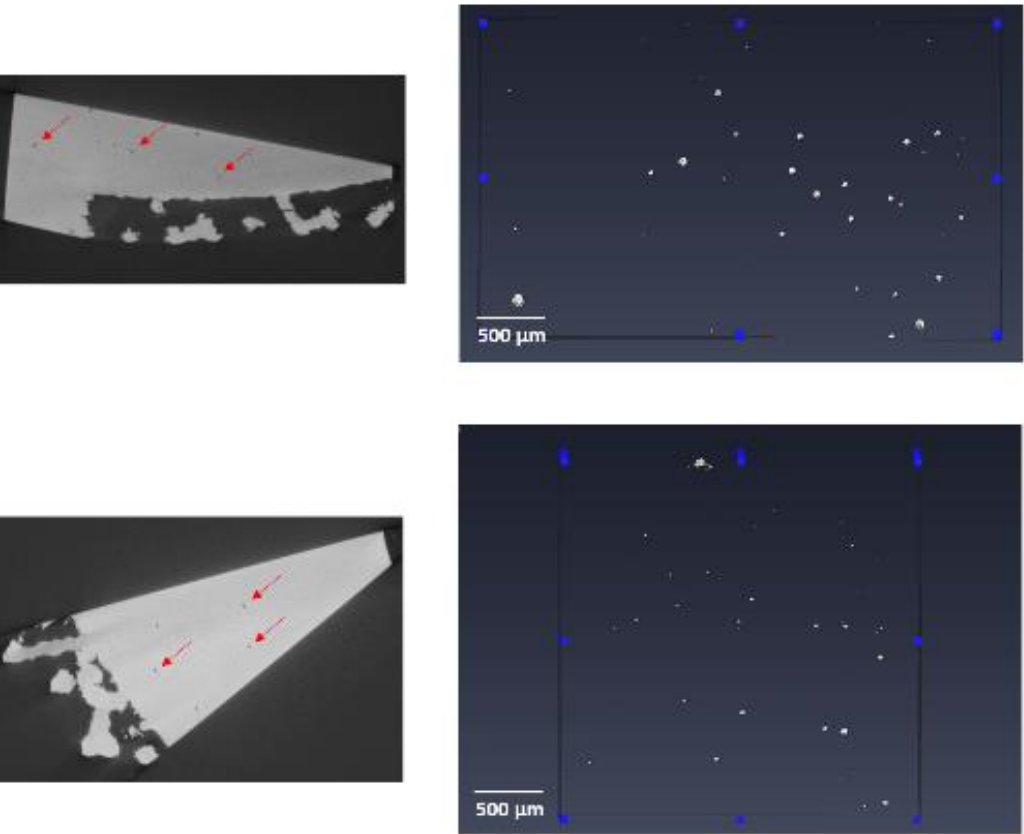

(c)

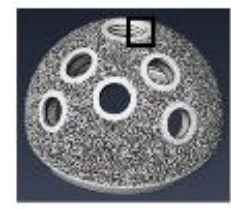

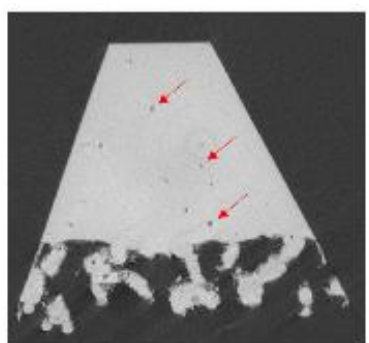

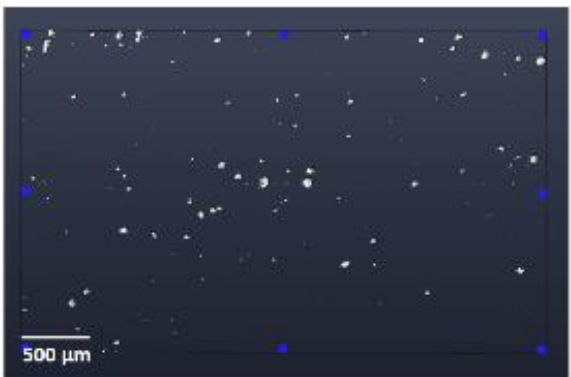

Figure 5 -Images showing the cavities found in the samples obtained from the $3 D$ printed cups: (a) Delta TT, (b) Mpact 3D Metal and (c) Trident II Tritanium. From left to right, the volume rendering of the cups, a cross-section of the sample sectioned from the central hole region where the cavities are visible (red arrows) and the distribution of the cavities in that sample are shown. (EBM - electron beam melting; LRM - laser rapid manufacturing). 


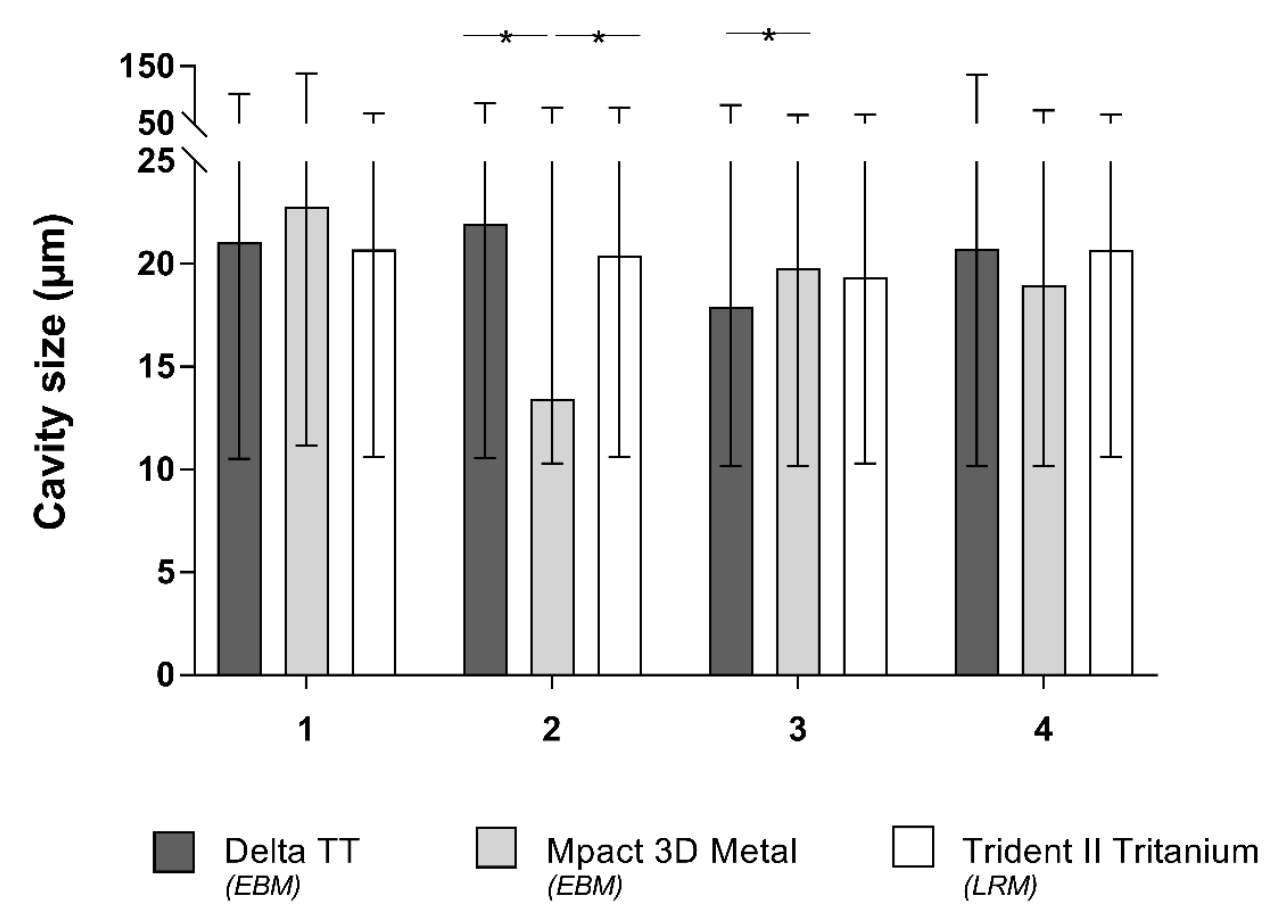

Figure 6 - Bar charts of the median (range) size of the cavities found in the $3 D$ printed cups grouped by area on the cups (1 - central hole; 2 -screw hole; 3 -porous; 4 -edge). Significant differences (*) were found between Delta TT and Mpact 3D Metal and between Trident II Tritanium and Mpact 3D Metal in the screw hole area, whilst between Delta TT and Trident II Tritanium in the porous area. 


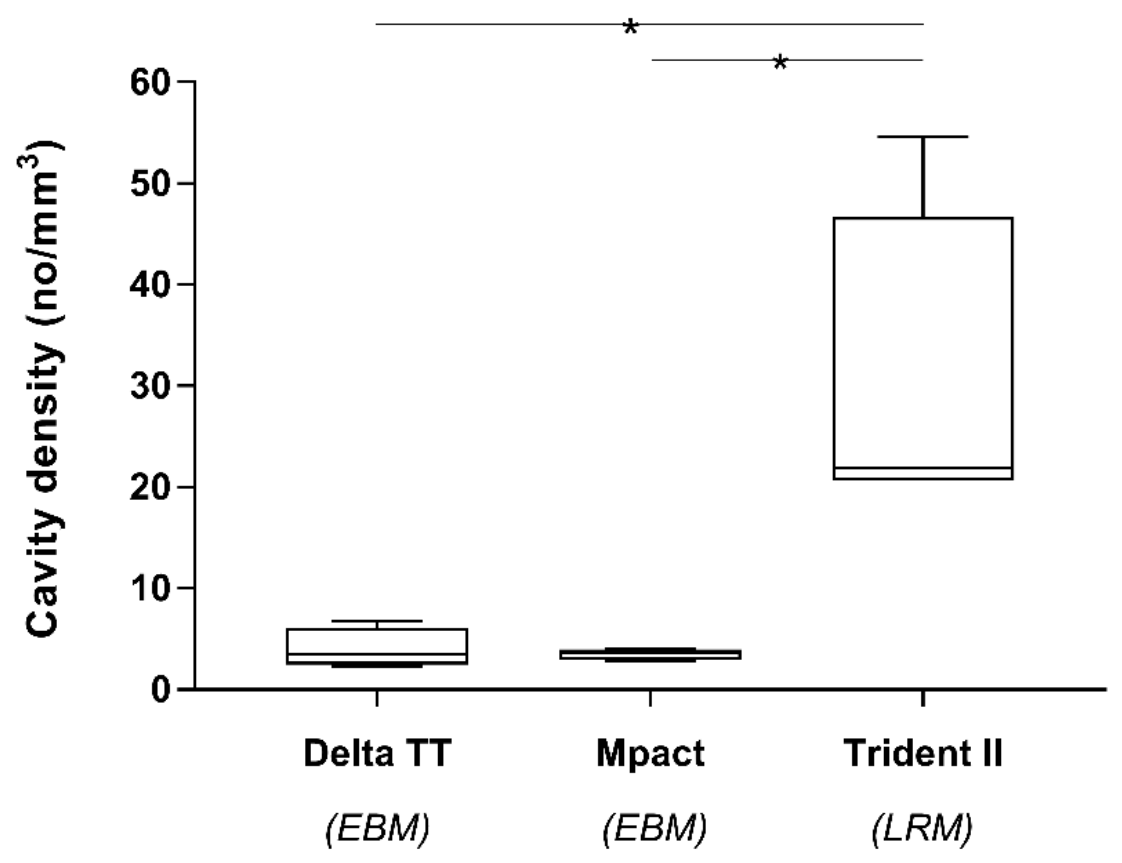

Figure 7 - Box plots showing the cavity density (number of cavities per $\mathrm{mm}^{3}$ ) in the $3 D$ printed cups; significantly higher density (*) was found in the Trident II Tritanium cup. 


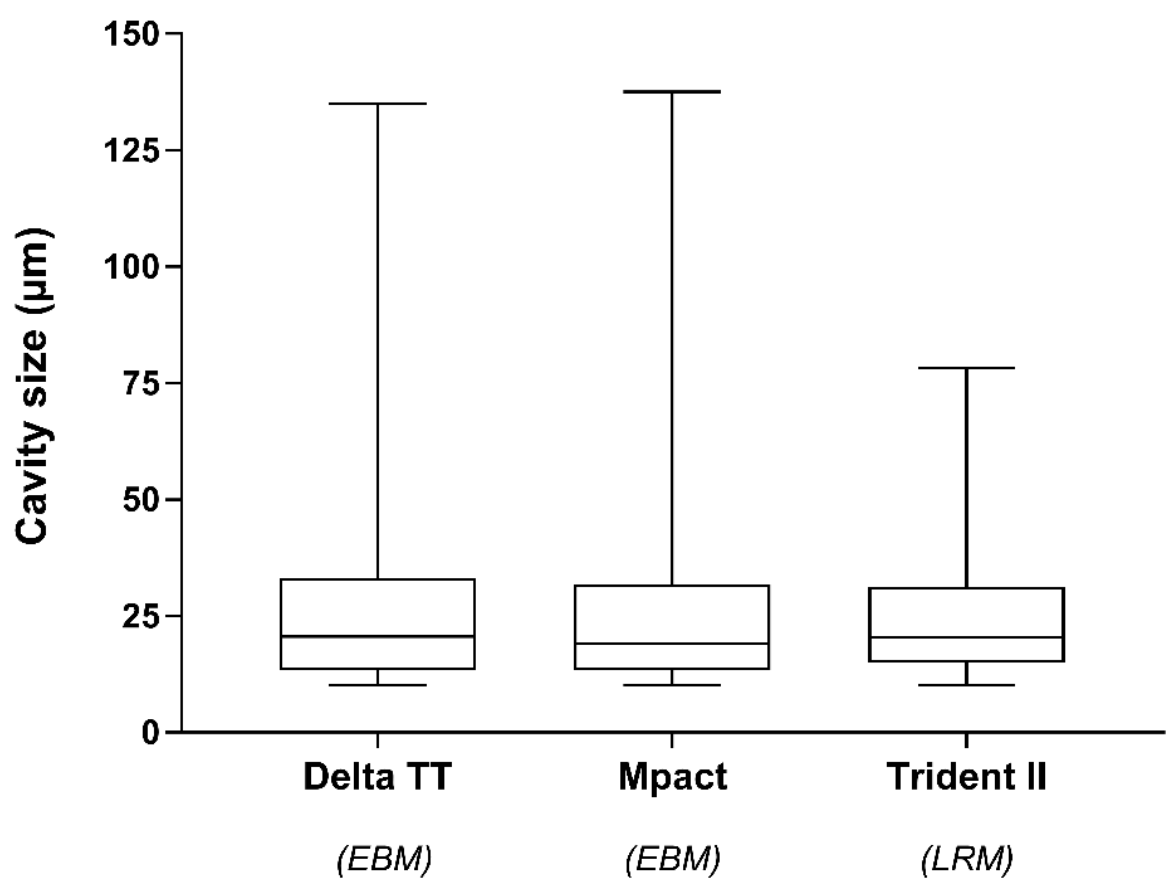

Figure 8 -Box plots showing the distribution of the size of the cavities found in the $3 D$ printed cups. No significant difference was found among the three cups. 


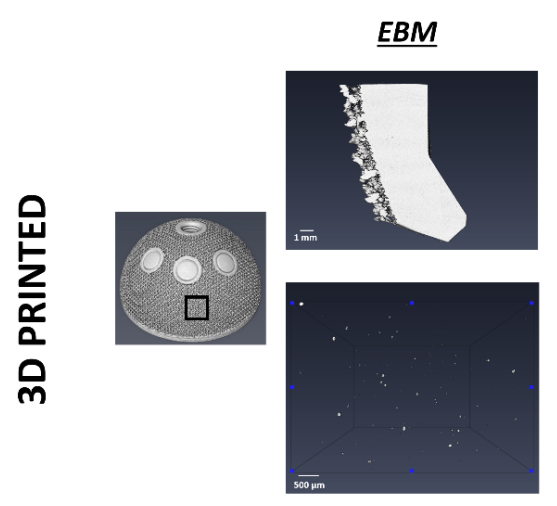

(a)

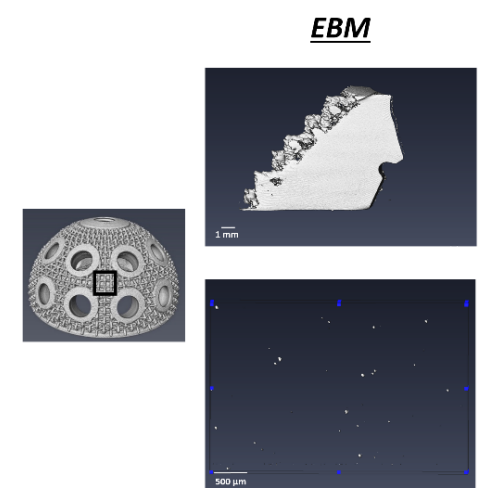

(b)

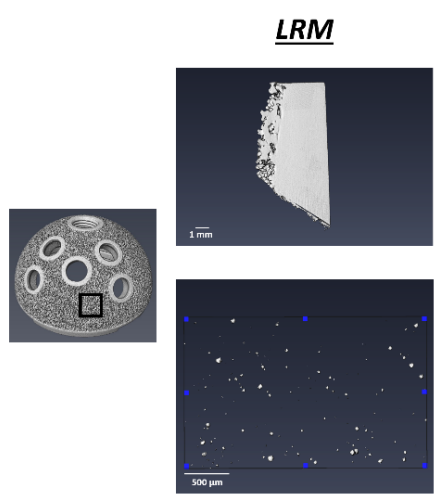

(c)

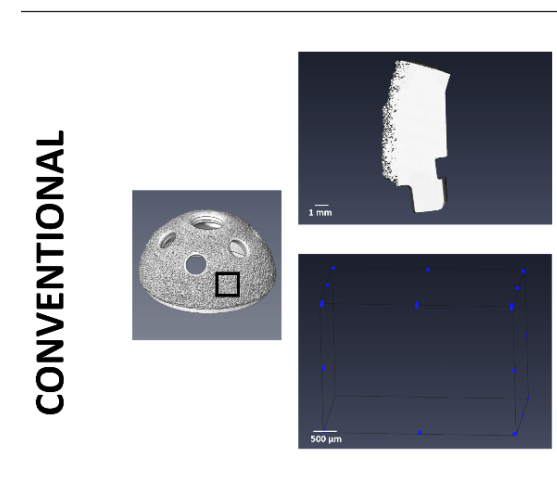

(d)

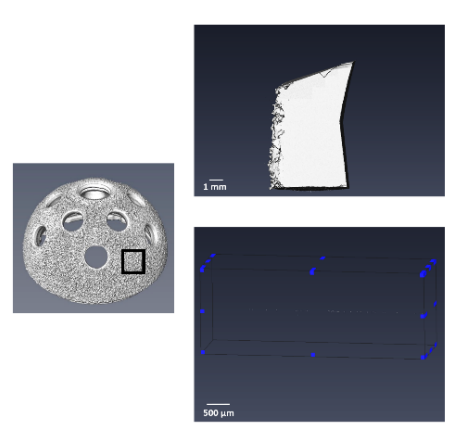

(e)

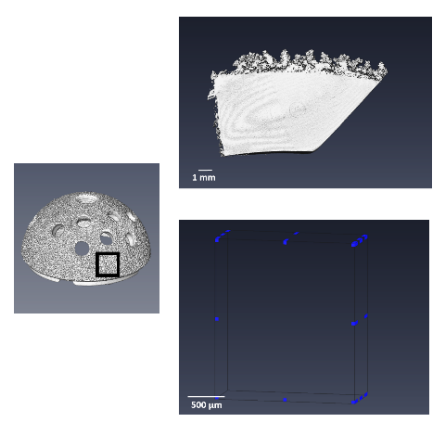

(f)

Figure 9 -Images comparing the outcomes from the micro-CT analysis of corresponding samples sectioned from the porous regions of the cups: 3D printed - (a) Delta TT, (b) Mpact 3D Metal, (c) Trident II Tritanium; conventional - (d) Pinnacle Porocoat, (e) Pinnacle Gription, (f) Trident I Tritanium. The volume rendering of the whole cup and the sectioned sample, together with the distribution of the cavities represented as material, are shown for each implant. The conventional cups showed absence of distinguishable structural cavities, unlike the 3D printed cups. 